http://jmscr.igmpublication.org/home/

ISSN (e)-2347-176x ISSN (p) 2455-0450

crossref DOI: https://dx.doi.org/10.18535/jmscr/v7i7.132

Journal Of Medical Science And Clinical Research

\title{
Primary Caregivers of Patients with Schizophrenia
}

\author{
Author \\ Dr Neha Ramsinghani Hotani* \\ Senior Resident, Department of Psychiatry, Government Medical College, Thrissur, India \\ *Corresponding Author \\ Dr Neha Ramsinghani Hotani \\ Senior Resident, Department of Psychiatry, Government Medical College, Thrissur, India
}

\begin{abstract}
Background: The key person who provides the most care and support to the patient is defined as the principal caregiver. Women, and particularly mothers, are the principal caregivers in schizophrenia.

Aim: To find out who are the primary caregivers of patients with schizophrenia.

Methods: Seventy six primary caregivers of patients with schizophrenia admitted under a general hospital psychiatry unit were interviewed by a clinician trained in Psychiatry. Socio demographic and other relevant details were collected using the study proforma.
\end{abstract}

Results: Majority of the caregivers (82.9\%) were females and their mean age was 52.5 years. All caregivers were family members and were most often mothers (56.6\%).

Conclusion: It was found that almost all relatives within the family served as caregivers fathers, mothers, husbands, wives, children, siblings, daughter-in-laws, sons-in-law. Majority of caregivers were parents, mostly mothers.

Keywords: Caregiving; Caregivers; Schizophrenia; Relative.

\section{Introduction}

A family member receiving the diagnosis of a psychiatric illness especially schizophrenia, is a turning point for the family. Most of the families are not prepared to deal with such situations. ${ }^{1}$ Schizophrenia is often a chronic and disabling psychiatric disorder and it affects one out of hundred people globally. The onset of schizophrenia is often described as catastrophic and burdening by the family members.

Caregiving is a basic component of human nature and forms an essential element of close relationships. It becomes more important and relevant in countries like India, where formal health care services have serious limitations due to poor infrastructure and manpower shortage. ${ }^{2}$ The key person who provides the most care and support to the patient is defined as the principal caregiver. Women, and particularly mothers, are the principal caregivers in schizophrenia. Mostly the caregivers are middle-aged mothers who are either married or cohabiting, have attended some or all of primary school, working either as selfemployed, farmers, or unskilled labourers. A survey $^{3}$, found that more than two third of caregivers $(68 \%)$ are the parents or step-parents while $12 \%$ were siblings, $7 \%$ spouses and $7 \%$ children or grandchildren of the affected person. Majority of studies have reported that the primary caregiver is likely to be a woman in most of the 
case. They are most likely to be mothers, sisters or wives. ${ }^{4}$

Caregivers have to sacrifice their basic needs like sleep, exercise, nutrition, which can have impact on caregiver's physical health. Apart from physical health consequences there are mental health consequences too with an increased risk of depression, insomnia, and anxiety. According to a study female caregivers experienced more anxiety/depression than men and faced more financial problems. ${ }^{5}$

\section{Objectives}

To find who are primary caregivers of persons suffering from schizophrenia.

\section{Methodology}

We used a cross sectional study design. The study participants were recruited from the inpatient services of the Department of Psychiatry Government Medical College, Thrissur. We identified individuals aged 18 to 50 years who were ill for more than one year and met the ICD10 criteria for the diagnosis of schizophrenia. The primary caregivers of these patients were identified. A person was considered as the primary caregiver if that person lived with the patient for the past one year and was primarily responsible for the care.

The research protocol had the ethical approval from the Institutional Review Board. We invited the caregivers to take part in the study. All those who gave informed consent were recruited. They were interviewed by a clinician trained in psychiatry. The study was done over a period of one year from August 2014 to July 2015. All consenting eligible caregivers were recruited. Socio demographic and other relevant details were collected using the study proforma.

\section{Results}

We recruited seventy six primary caregivers of individuals hospitalized for treatment of schizophrenia. Most of the subjects with Schizophrenia were males $(60.5 \%)$ and their mean age was 34.7 years. Majority of the caregivers $(82.9 \%)$ were females and their mean age was 52.5 years. All caregivers were family members and were most often mothers $(56.6 \%)$

\section{Conclusion}

Mean age of patients in our study was 34.78 years (SD 9.63), majority of patients were males, this is similar to studies by Lasebikan $\mathrm{V}$ et al. ${ }^{6}$ and Winefield HR et al. ${ }^{7}$ Mean age of caregivers was 52.58 years (SD 13.01) similar age distribution is also seen in studies by Lasebikan $\mathrm{V}$ et al. $^{6}$ and Martín J et al. ${ }^{8}$ on schizophrenia caregivers. About half of the caregivers were above 50 years of age which, indicates the involvement of older caregivers, a finding reported by an Indian study by Janardhana $\mathrm{N}$ et al. ${ }^{9}$ Majority of caregivers were women and this is in agreement with many studies. Majority of caregivers were parents, mostly mothers. Many studies ${ }^{3}$ conducted in India and abroad have shown similar finding. It was found that almost all relatives within the family served as caregivers fathers, mothers, husbands, wives, children, siblings, daughter-in-laws, sonsin-law this is in agreement with study by Janardhana $\mathrm{N}$ et al. ${ }^{9}$

\section{References}

1. Janardhana N, Shravya R, Naidu DM, Saraswathi L, Seshan V. 'Caregivers in Community Mental Health' Basic Needs India; 2008.

2. Vasudeva S, Sekhar C, Rao P. Caregivers burden of patients with schizophrenia and bipolar disorder: A sectional study. Indian J Psychol Med. 2013;35(4):352-7.

3. Schizophrenia: Public Attitudes, Personal Needs Views from People Living with Schizophrenia, Caregivers, and the General Public Analysis and Recommendations June 10, 2008 nami

4. Montero I, Masanet MJ, Lacruz M, Bellver F, Asencio A, García E. Family intervention in schizophrenia: Long-term 
effect on main caregivers. Actas Esp Psiquiatr. 2006;34:169-74.

5. Flyckt L, Lothman A, Jorgensen L, Rylander A, Koernig T. Burden of informal care giving to patients with psychoses: A descriptive and methodological study. Int $\mathrm{J}$ Soc Psychiatry. 2011;59(2):137-46.

6. Lasebikan V, Ayinde O. Family burden in caregivers of schizophrenia patients: Prevalence and socio-demographic correlates. Indian J Psychol Med. 2013;35(1):60-6.

7. Winefield HR, Harvey EJ. Determinants of psychological distress in relatives of people with chronic schizophrenia. Schizophr Bull. 1993;19(3):619-25.

8. Martín J, Padierna A, Van Wijngaarden B, Aguirre U, Anton A, Muñoz $\mathrm{P}$ et al. Caregivers consequences of care among patients with eating disorders, depression or schizophrenia. BMC Psychiatry. 2015;15(1)124.

9. Janardhana N, Raghunandan S, Naidu D, Saraswathi L, Seshan V. Care giving of people with severe mental illness: An Indian experience. Indian J Psychol Med. 2015;37(2):184-94. 